\title{
MODEL MOBILE POSITIONING SYSTEM BERBASIS ANDROID
}

\author{
Erwin Dwika Putra ${ }^{1}$, Erzi Hidayat ${ }^{2}$, Handrie Noprisson ${ }^{3}$ \\ ${ }^{1,3}$ Program Studi Teknik Infomatika, Fakultas Teknik, Universitas Muhammadiyah Bengkulu \\ Jl. Bali, Kota Bengkulu, 38119 INDONESIA \\ (telp: 0736-22765; fax: 0736-26161) \\ ${ }^{2}$ Program Studi Teknik Infomatika, Fakultas Sains dan Teknologi, \\ Universitas Islam Negeri Sultan Syarif Kasim Riau \\ Jl.H.R.Soebrantas No.155 KM 18, Simpang Baru Panam, Pekanbaru 28293 INDONESIA \\ (e-mail: tif [at] uin-suska.ac.id) \\ ${ }^{1}$ erwindwikap@gmail.com \\ erzihidayat26@gmail.com \\ ${ }^{3}$ handrie.tif@gmail.com
}

\begin{abstract}
Abstrak: Seiring perkembangan teknologi mobile, aplikasi berbasis positioning system yang memanfaatkan Global Positioning System (GPS) untuk penentuan posisi semakin populer terutama pada platform android. Beberapa penelitian mengenai pengembangan aplikasi telah menerapkan mobile positioning system, namun belum ada yang membahas model mobile position system secara spesifik. Penelitian fokus fitur yang ada mobile position system yang dilakukan dengan memodelkan sistem dalam bentuk Unified Modelling Language (UML). Metodologi yang digunakan untuk membangun model sistem adalah metodologi prototyping yang diakhiri dengan evaluasi model sistem dengan menggunakan teknik blackbox testing. Penelitian ini telah berhasil memodelkan mobile positioning system yang terdiri 21 class yang mempresentasikan aktifitas dari 6 use-cases yang telah didefinisikan. Hasil dari penelitian ini diharapkan dapat dijadikan acuan dalam pengembangan aplikasi mobile berbasis positioning system lainnya.
\end{abstract}

Kata kunci: mobile positioning system, global positioning system, unified modeling language, mobile technology, prototyping.

\begin{abstract}
Mobile technology was leading to develop application which applied Global Positioning System (GPS) for defining location. Some researchers have developed many kind of application by applying mobile positioning system. However, there is no research paper that particularly explained and elaborated about mobile positioning system. This research attempted to focus on mobile positioning system that was modeled into Unified Modeling Language (UML). Research methodology of this research adapted prototyping methodology and it was ended by evaluation phase by conducting black-box testing scenarios. This research has been modeled mobile positioning system into 21 classes to represent all activities of the six defined use-cases. The result of research can be used to develop new application in which adapted positioning system.
\end{abstract}

Keywords: mobile positioning system, global positioning system, unified modeling language, mobile technology, prototyping.

\section{Pendahuluan}

Teknologi seluler yang berkembang sangat pesat mendorong perkembangan perangkat pintar yang dapat menjalankan berbagai aplikasi (multitasking) pada sistem operasi tersendiri seperti sebuah komputer. Sistem operasi ponsel cerdas yang sedang berkembang pesat belakangan ini yaitu Android. Menurut catatan International Data Corporation (IDC) sampai dengan 8 Agustus 2012, pangsa pasar Android yang didukung oleh Google telah mencapai 68,1\% dari pangsa pasar smartphone di seluruh dunia [1].

Pada saat sekarang ini hampir semua perangkat mobile sudah terintegrasi dengan Global Positioning System (GPS) sehingga sangat 
memungkinkan untuk mengetahui posisi handset harus memiliki fasilitas untuk mengakses keberadaan perangkat mobile lain. Hal ini GPS seperti yang dapat dilihat pada Gambar 1. mendorong munculnya berbagai aplikasi berbasis positioning system yang memanfaatkan GPS untuk penentuan posisi.

Studi dan penelitian terkait penentuan lokasi dengan penggunaan GPS telah dilakukan oleh Chon dan Cha (2011) yang membangun aplikasi mengenai LifeMap [2], penelitian oleh Singhal dan Shukla (2012) mengenai GPS dan web services [3], serta penelitian oleh Shin et al. (2010) mengenai indoor WiFi positioning [4].

Mengacu pada penelitian sebelumnya tersebut, penelitian ini mencoba memaparkan mengenai model positioning system pada platform android mengingat semakin banyaknya pengembangan aplikasi berbasis positioning system, diantaranya aplikasi Friend Positioning [5], Mobile Location Service Design [6], Children Tracking System [7] dan Mobile Disaster Management System [8].

Meskipun telah banyak diterapkan dan digunakan, namun belum ada secara spesifik membahas model mobile position system ini. Padahal pemodelan ini terus digunakan pada pengembangan aplikasi atau sistem baru pada perangkat mobile. Hasil pemodelan ini yang diharapkan dapat dijadikan acuan untuk mempermudah dalam pengembangan aplikasi berbasis mobile positioning system.

\section{LANDASAN TEORI}

\section{A. Advanced Positioning}

Pada umumnya menggunakan teknologi Assisted-Global Positioning System (A-GPS). AGPS juga merupakan metode yang berbasis pada waktu. Pada metode ini, akan dilakukan pengukuran waktu tiba dari sebuah sinyal yang dikirim dari tiga buah satelit GPS. Hal ini berarti

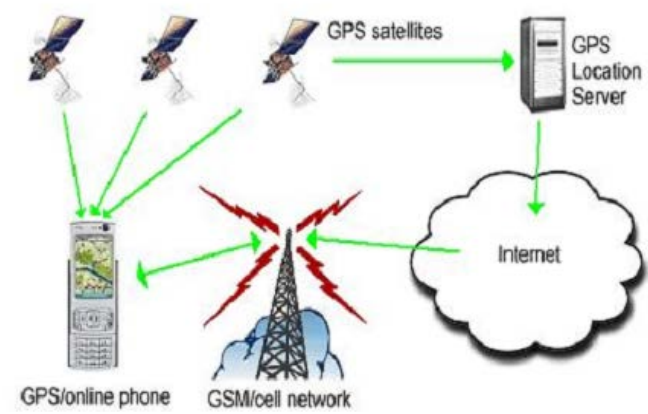

Gambar 1. Arsitektur Advanced Positioning [3]

\section{B. Unified Modelling Language}

Unified Modeling Language (UML) adalah pemodelan sistem yang digunakan untuk pengembangan sistem yang berorientasi objek [9]. Dalam penelitian ini diagram UML yang digunakan yaitu use case diagram dan class diagram.

Use case diagram merupakan gambaran aktivitas yang dilakukan pengguna terhadap sebuah sistem [9]. Komponen utama dalam diagram ini adalah use case, aktor dan relationship. Diagram ini biasanya digunakan sebagai overview dari keseluruhan requirement yang dipresentasikan dalam bentuk essential model, mempresentasikan business model dan mempresentasikan batasan dari pengembangan sistem. [10].

Sedangkan class diagram merupakan model statis yang menunjukkan seluruh class pada sistem beserta hubungan antar satu dengan yang lainnya [9]. Komponen pada class diagram antara lain class (atribut dan method) dan hubungan (relationship) [10].

\section{Metodologi Penelitian}

Sub-bab ini menjelaskan tahapan-tahapan dalam pengembangan model mobile positioning 
system yang mengadaptasi tahapan metodologi prototyping. Dalam penelitian ini terdiri dari enam tahapan penelitian dimulai dengan pendefinisian model sistem yang dikembangkan dan diakhiri dengan tahap analisis hasil pemodelan dan evaluasi seperti yang dipresentasikan pada Gambar 2.

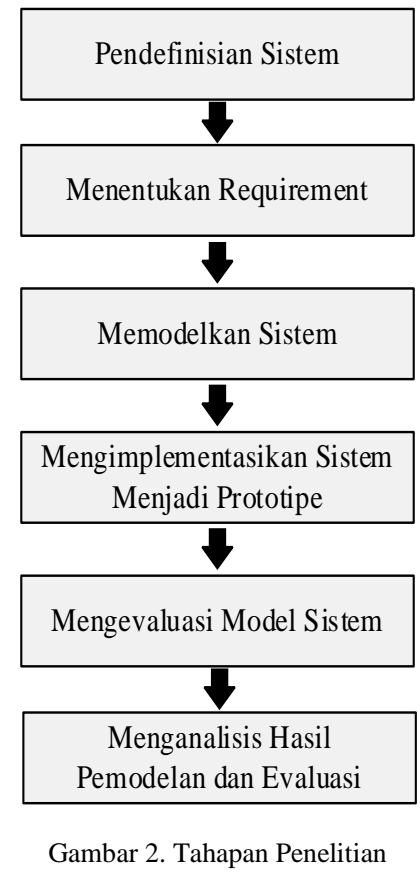

Pada tahap pendefinisian sistem, ditentukan batasan-batasan sistem dan penelitian terkait yang membahas mengenai mobile positioning system. Dari hasil definisi tersebut, kemudian ditentukan requirement yang sesuai yang kemudian dimodelkan dengan menggunakan Unified Modelling System (UML).

Untuk mempemudah evaluasi model sistem, pemodelan kemudian implementasikan dalam bentuk prototipe sistem yang dikembangkan untuk platform Android. Prototipe kemudian dievaluasi dengan menggunakan skenario untuk menguji fungsionalitas sistem. Hasil dari pemodelan dan evaluasi kemudian dianalisis dan dijabarkan sebagai hasil dari penelitian.

\section{Model Mobile Positioning SysteM}

Model mobile positioning system yang dibahas dalam penelitian ini adalah model sistem yang digunakan untuk mengetahui posisi mobile berdasarkan koordinat lokasi. Dalam penelitian ini, mobile positioning system memanfaatkan teknologi GPS sebagai alat untuk mendapatkan koordinat posisi dan teknologi online map yang disediakan oleh Google untuk mempresentasikan posisi yang telah tersimpan dalam sistem.

\section{A. Arsitektur}

Mobile positioning system terdiri dua subsistem utama yang saling terhubung yaitu, subsistem tracker yang digunakan untuk memonitor posisi mobile yang telah didaftarkan sebelumnya dan sub-sistem tracking yang dibenamkan pada mobile yang akan dimonitor dan dirancang berjalan secara background service untuk memberikan nilai lokasi dalam durasi waktu tertentu secara berkala pada server online dan disimpan ke dalam database. Secara lebih detail mengenai deskripsi arsitektur sistem ini dapat di lihat pada Gambar 3 dibawah ini.

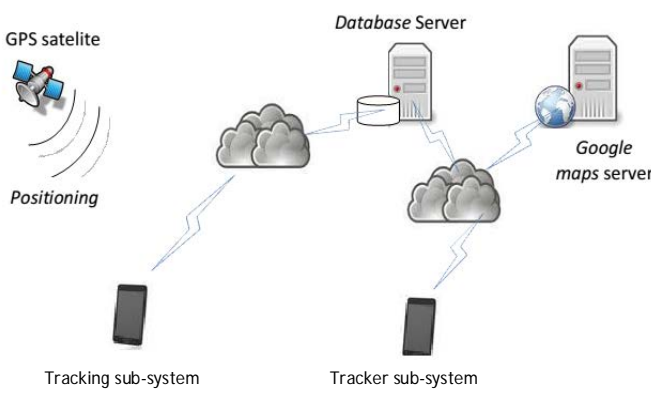

Gambar 3. Arsitektur Mobile Positioning System

Berdasarkan Gambar 3 diatas dapat dilihat proses kerja mobile positioning system, terdiri dari sub-sistem tracking dan sub-sistem tracker yang masing-masing dibenamkan pada perangkat mobile yang berbeda yang dijelaskan sebagai berikut: 
Sub-sistem tracking berjalan sebagai service yang memiliki fungsi sebagai pengirim nilai koordinat melalui httpconnection, untuk mendapatkan nilai koordinat maka GPS sangat berperan penting untuk mendapatkan nilai posisi, kemudian nilai koodinat tersebut akan dikirimkan ke server online secara terus menerus berdasarkan rentang durasi waktu yang telah ditentukan.

Sub-sistem tracker digunakan untuk mengambil nilai lokasi pada server online yang terhubung dengan koneksi internet sebagai data utama untuk menampilkan data lokasi terbaru dari perangkat mobile yang dimonitor, sub-sistem yang akan digunakan untuk mengetahui posisi perangkat mobile yang dimonitor pada Google Maps.

\section{B. Pemodelan UML}

Diagram UML yang digunakan untuk memodelkan mobile positioning system yaitu use case diagram dan class diagram. Pada diagram use case terdapat enam use case utama yang mempresentasikan aktivitas yang ada pada mobile positioning system antara lain register, send current position, check last position, check history track, check map dan get direction. Aktor yang terlibat dalam sistem ini adalah main user yang merupakan aktor yang memonitoring mobile device yang digunakan oleh secondary user.
Keseluruhan komponen use case diagram dapat dilihat pada Gambar 4.

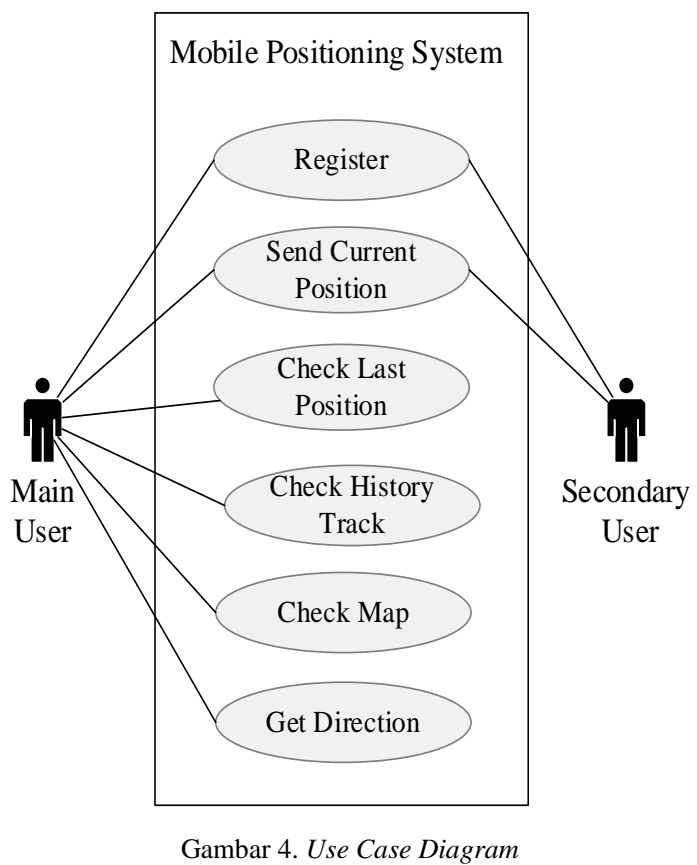

Sedangkan class diagram menggambarkan struktur dan deskripsi class, package, dan objek yang saling terhubung. Ada sebanyak 21 class yang digunakan untuk pengembangan mobile positioning system antara lain UserListViewMyActivity, LokasiTeman Posisi, JSONFunction, Konfigurasi TampilkanPeta, ListAnggota, ListPosisi, GoogleParser, XMLParser, StringParser, Route dan lainnya seperti yang terlihat pada Gambar 5. 


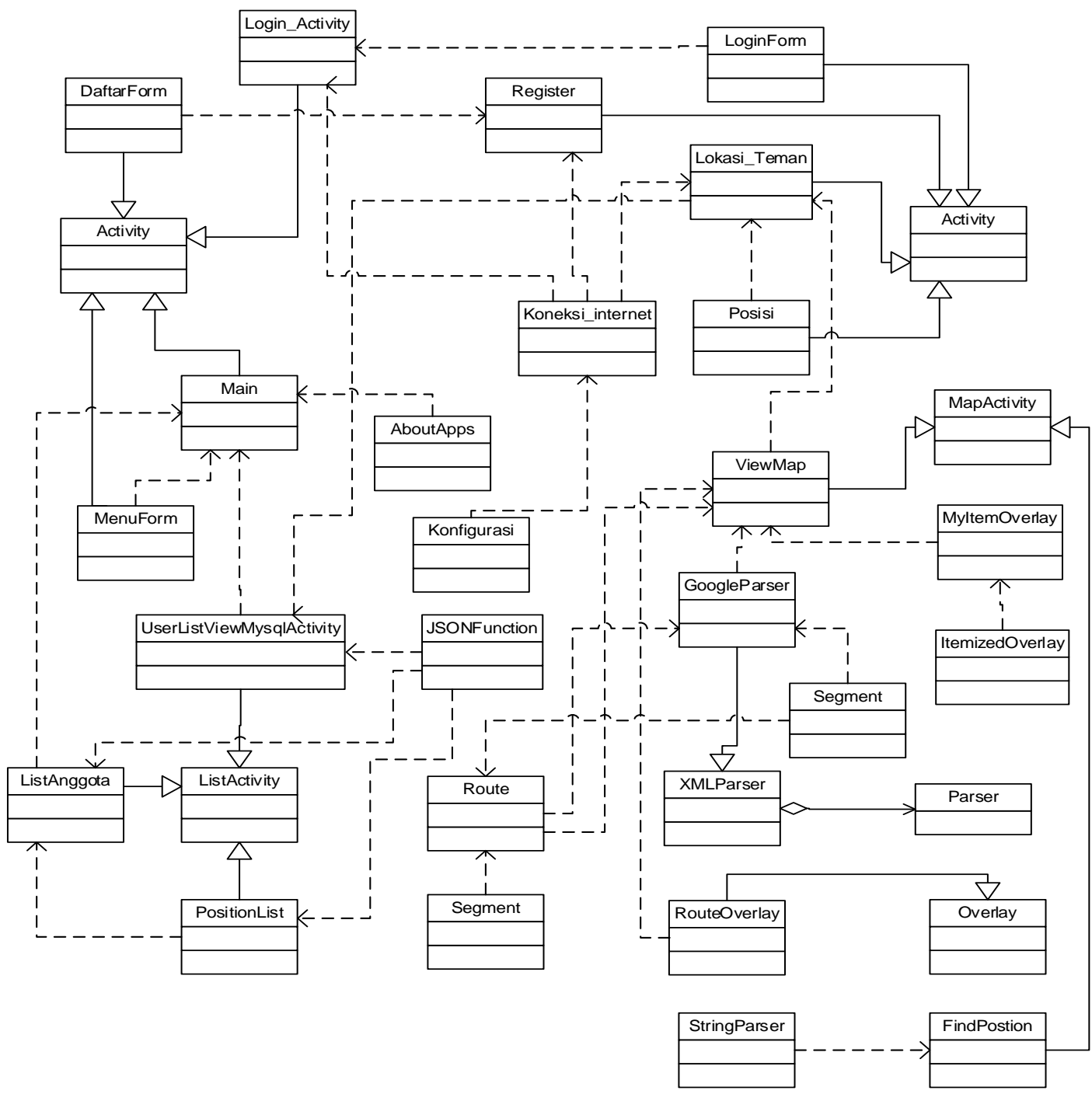

Gambar 5. Class Diagram

Berikut detail beberapa class yang ada pada Gambar x yang berisi nama class, atribut, dan method, yang dapat dilihat pada Tabel 1 di bawah ini.

Tabel 1. Detail Class Diagram

\begin{tabular}{|c|c|c|}
\hline Class & Atribut & Method \\
\hline $\begin{array}{l}\text { Find } \\
\text { Position }\end{array}$ & $\begin{array}{l}\text { - lat : String } \\
\text { - lon : String } \\
\text { - nama_teman: } \\
\text { String } \\
\text { - locationmanager: } \\
\text { LocationManager } \\
\text { - yourLat: String } \\
\text { - yourLon: String } \\
\text { - jarak: String } \\
\text { - textlokasi: } \\
\text { TextView } \\
\text { - textlokasisaya: } \\
\text { TextView } \\
\text { posisi : Posisi }\end{array}$ & $\begin{array}{l}\text { - } \text { onCreate(Bundle } \\
\text { savedInstanceState: } \\
\text { void } \\
\text { - } \text { updateposisi: void } \\
\text { - } \text { onproviderDisabled } \\
\text { (String provider): } \\
\text { void } \\
\text { - onProvideEnabled } \\
\text { (String provider): } \\
\text { void } \\
\text { - onStatusChanged(S } \\
\text { tring provider, int } \\
\text { status, Bundle } \\
\text { xtras): void }\end{array}$ \\
\hline
\end{tabular}

\begin{tabular}{|c|c|c|}
\hline Class & Atribut & Method \\
\hline $\begin{array}{l}\text { JSON } \\
\text { Function }\end{array}$ & $\begin{array}{l}\text { - } \text { is :InputStream } \\
\text { - result : String } \\
\text { - jArray : } \\
\text { JSONObject }\end{array}$ & $\begin{array}{l}\text { - getJSONFromURL } \\
\text { (String url) }\end{array}$ \\
\hline $\begin{array}{l}\text { Google } \\
\text { Parser }\end{array}$ & - distance: int & $\begin{array}{l}\text { - GoogleParser(Strin } \\
\text { g feedUrl) } \\
\text { - Parse() : Route } \\
\text { - } \text { convertStreamtoStr } \\
\text { ing(final } \\
\text { InputStream } \\
\text { input): String } \\
\text { - decodePolyline(fin } \\
\text { al String poly): } \\
\text { List<Geopoint }>\end{array}$ \\
\hline Route & $\begin{array}{l}\text { - Points: } \\
\text { List<GeoPoint> } \\
\text { - Name: String } \\
\text { - Segment: } \\
\text { - List<Segment> } \\
\text { - Copyright: String } \\
\text { - Warning:String } \\
\text { - Country: String } \\
\text { - Length: int }\end{array}$ & $\begin{array}{ll}\text { - } & \text { Route() } \\
\text { - } & \text { addPoint(final } \\
& \text { GeoPoint p): void } \\
\text { - } & \text { addPoints(final } \\
& \text { List< }<\text { GeoPoint }> \\
\text { point): void } \\
\text { - } \text { getPoint(): } \\
\text { List<GeoPoint }> \\
\text { - } \text { addSegment(final }\end{array}$ \\
\hline
\end{tabular}




\begin{tabular}{|c|c|c|}
\hline Class & Atribut & Method \\
\hline & - Polyline: String & $\begin{array}{ll} & \text { Segment s): void } \\
\text { - } & \text { getSegment()List< } \\
& \text { Segment }> \\
\text { - } & \text { setName(final } \\
& \text { String name): void } \\
\text { - } & \text { getName(): String }\end{array}$ \\
\hline
\end{tabular}

Untuk menambah gambar mengenai model mobile positioning system yang dibangun berikut salah satu fungsi yang hasil implementasi kode dari class FindPosition seperti yang terlihat pada Gambar 6 berikut ini.

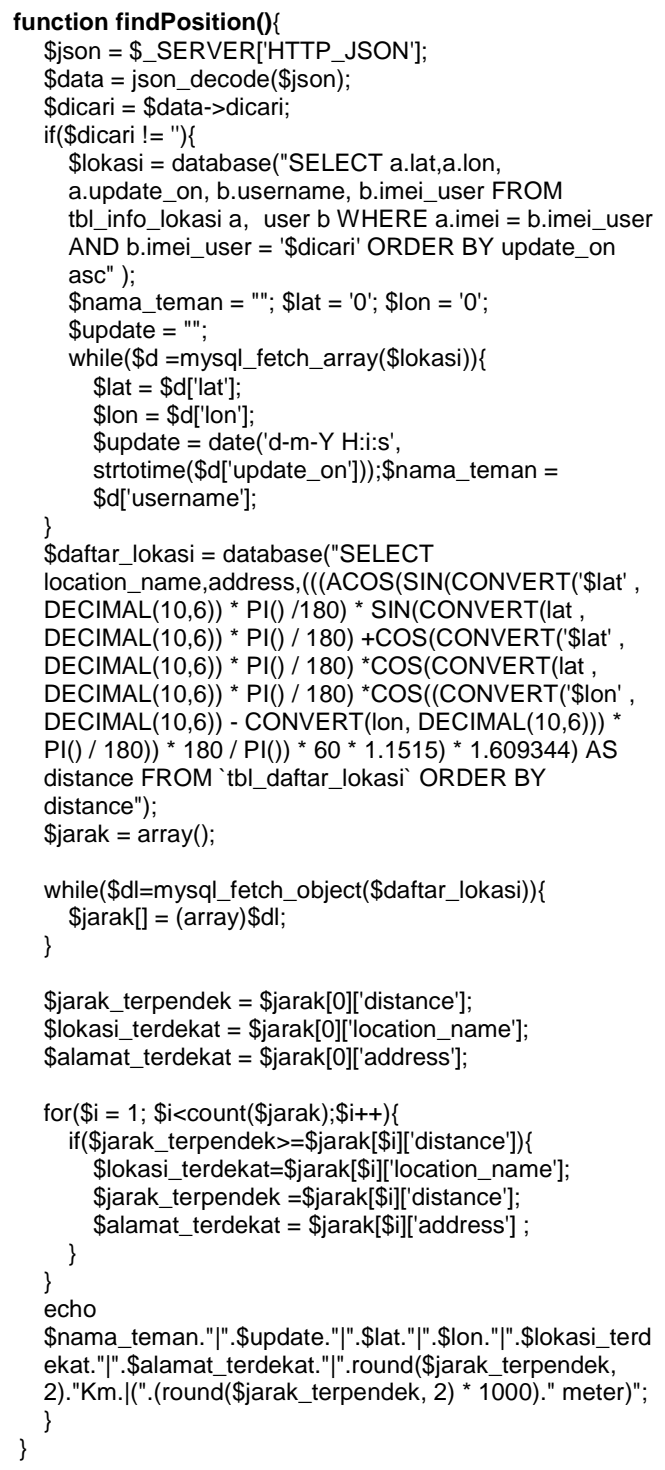

Gambar 6. Arsitektur Mobile Positioning System

\section{Antar Muka}

Berikut ini dijelaskan tentang antar muka dari aplikasi mobile position system pada sistem operasi Android yang terdiri dua sub-sistem yaitu subsistem tracker dan sub-sistem tracking. Desain antarmuka sub-sistem tracking terdiri dari 3 menu utama antara lain register pengguna, start service dan exit seperti yang terlihat pada Gambar 7.

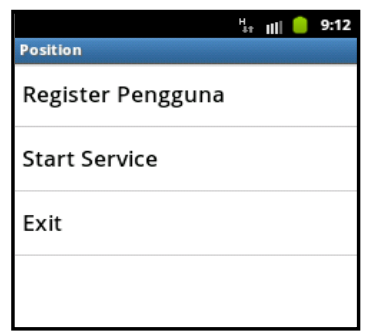

Gambar 7. Antarmuka Sub-Sistem Tracking

Sedangkan untuk desain antarmuka sub-sistem tracking terdiri dari 4 menu utama antara lain posisi mobile, tracking, about dan exit seperti yang terlihat pada Gambar 8. Untuk detail masingmasing antarmuka dari menu utama akan dijelaskan selanjutnya.

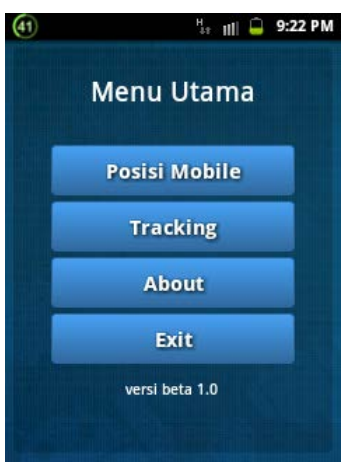

Gambar 8. Antarmuka Sub-Sistem Tracker

Gambar 9 merupakan desain antarmuka dari halaman register pengguna yang digunakan untuk mendaftarkan pengguna atau mobile yang dimonitoring posisi keberadaanya. Identitas mobile ditentukan berdasarkan nama pengguna dan kode IMEI (International Mobile Equipment Identity). 


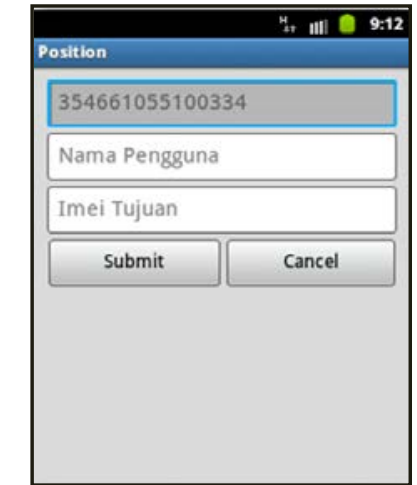

Gambar 9. Antarmuka Register Pengguna

Semua mobile yang sudah terdaftar dalam sistem kemudian akan tampil dalam mobile positioning system system dalam bentuk list yang ditampilkan pada Gambar 10.

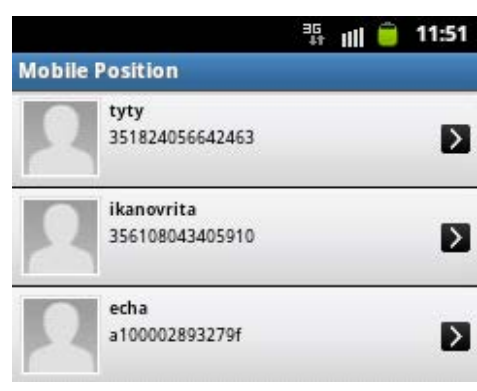

Gambar 10. Antarmuka Mobile List

Setiap mobile yang telah terdaftar dan muncul pada mobile list dapat dimonitor keberadaannya dan riwayat posisi terakhir yang dapat dilihat pada menu history track seperti yang digambarkan pada Gambar 11.

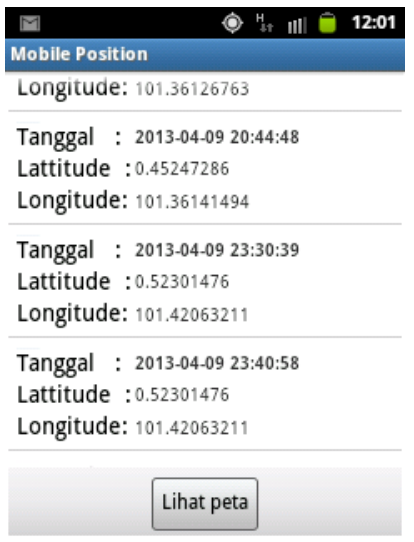

Gambar 11. Antarmuka History Track
Untuk mengetahui lebih detail mengenai koordinat longitude, latitude dan jarak mobile yang dimonitoring dapat menggunakan melihat detail posisi dari mobile seperti terlihat pada Gambar 12.

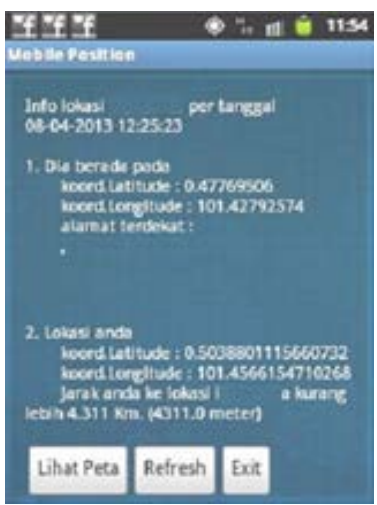

Gambar 12. Antarmuka Detail Posisi Mobile

Untuk mempermudah pengguna dalam mengetahui posisi mobile tertentu mobile position system juga dilengkapi dengan fasilitas map dengan memanfaatkan fasilitas dari Google Maps seperti yang terlihat pada Gambar 13.

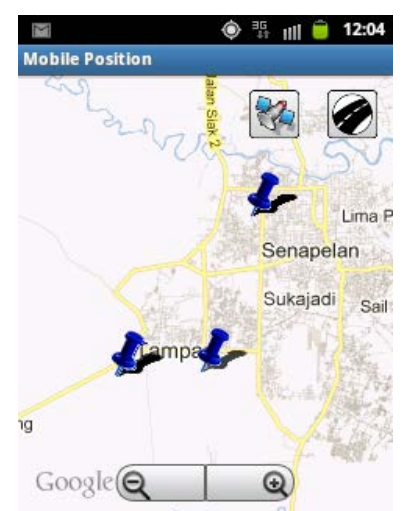

Gambar 13. Antarmuka Check Map

\section{EVALUASI}

Evaluasi yang dilakukan bertujuan untuk mengetahui mobile positioning system yang telah dibangun dapat beroperasi pada perangkat berplatform Android dengan berbagai versi. Dalam evaluasi ini dilakukan pada tiga perangkat mobile yang lebih detail dapat dilihat pada Tabel 2. 
Jurnal Pseudocode, Volume III Nomor 2, September 2016, ISSN 2355-5920

Tabel 2. Perangkat Mobile Pada Tahap Evaluasi

\begin{tabular}{|l|l|}
\hline \multicolumn{1}{|c|}{ Nama } & \multicolumn{1}{c|}{ Spesifikasi } \\
\hline Mobile A & $\begin{array}{l}\text { Samsung Galaxy y } \\
\text { Gingerbread.DXLB1 (2.3.6) }\end{array}$ \\
\hline Mobile B & $\begin{array}{l}\text { Samsung Galaxy Mini } \\
\text { Froyo (2.2) }\end{array}$ \\
\hline Mobile C & $\begin{array}{l}\text { Smart Friend Andro } \\
\text { Gingerbread.DXLB1 (2.3.6) }\end{array}$ \\
\hline
\end{tabular}

Serangkaian skenario untuk mengevaluasi mobile positioning system dilakukan pada ketiga perangkat mobile yaitu Mobile A, Mobile B dan Mobile C. Beberapa contoh skenario evaluasi dapat dilihat pada Tabel 3.

Tabel 3. Skenario Evaluasi Sistem

\begin{tabular}{|l|l|l|}
\hline \multicolumn{1}{|c|}{ Skenario } & \multicolumn{1}{c|}{ Hasil } & \multicolumn{1}{c|}{ Keterangan } \\
\hline Koneksi ke server & Berhasil & - \\
\hline Daftar user & Berhasil & Data tersimpan \\
\hline Menu utama & Berhasil & $\begin{array}{l}\text { Halaman utama } \\
\text { tampil }\end{array}$ \\
\hline $\begin{array}{l}\text { Jalankan service } \\
\text { lokasi }\end{array}$ & $\begin{array}{l}\text { Data posisi } \\
\text { terkirim }\end{array}$ & $\begin{array}{l}\text { Service berjalan } \\
\text { pada background } \\
\text { aplikasi }\end{array}$ \\
\hline Koneksi ke server & Berhasil & - \\
\hline
\end{tabular}

Setelah dilakukan beberapa pengujian terhadap aplikasi yang telah dibangun, maka hasil evaluasi yang dapat dipaparkan antara lain:

1. Model mobile position system pada sub-sistem tracking telah mampu mengirimkan nilai posisi GPS ke server dari background service secara berkala.

2. Beberapa pengujian pada sub-sistem tracking mengalami kegagalan disebabkan beberapa kemungkinan, antara lain koneksi jaringan internet yang tidak stabil, respon dari server yang terlalu lama dan status GPS yang tidak aktif.

3. Model mobile position system pada sub-sistem tracker telah mampu membaca posisi lokasi mobile, menampilkan posisi keberadaan mobile pada Google Maps dan melakukan driving direction, serta melakukan track history posisi mobile yang terdaftar di server.

\section{KESIMPULAN}

Setelah menyelesaikan serangkaian tahapan analisis, perancangan dan implementasi pada aplikasi mobile phone position pada platform android, maka dapat diambil beberapa kesimpulan diantaranya adalah sebagai berikut:

1. Berhasil mengimplementasikan model mobile positioning system pada platform Android yang terdiri dari aktivitas utama yaitu register, send current position, check last position, check history track, check map dan get direction.

2. Pengujian pada beberapa perangkat Android yang berbeda Samsung Galaxy y, Galaxy mini dan Smartfren dengan versi sistem operasi 2.2 dan 2.3.6 memperlihatkan aplikasi berjalan dengan baik seperti berhasil mengirimkan informasi latitude dan longitude ke server online secara background service, berhasil menjalankan fitur tracking posisi dari waktu ke waktu namun memiliki kekurangan seperti pengguna hanya terbatas pada pengguna mobile dengan sistem operasi Android, selain itu juga penggunaan aplikasi hanya pada user yang aktif sehingga data posisi hanya dapat dikirimkan apabila pengguna mengaktifkan GPS di perangkat mobile.

\section{REFERENSI}

[1] R. K. Nistanto, “Apa Pertimbangan Utama Memilih Smartphone?,” Kompas Tekno, 2014. [Online]. Available:

http://tekno.kompas.com/read/2014/05/13/1536009/Apa. Pertimbangan.Utama.Memilih.Smartphone. [Accessed: 20-Aug-2016].

[2] J. Chon and H. Cha, "LifeMap: A smartphone-based context provider for location-based services," IEEE Pervasive Comput., vol. 10, no. 2, pp. 58-67, 2011.

[3] M. Singhal and A. Shukla, "Implementation of Location based Services in Android using GPS and Web Services,” Int. J. Comput. Sci. Issues, vol. 9, no. 1, 2012. 
Jurnal Pseudocode, Volume III Nomor 2, September 2016, ISSN 2355-5920

[4] B. J. Shin, K. W. Lee, S. H. Choi, J. Y. Kim, W. J. Lee, and H. S. Kim, "Indoor WiFi positioning system for Android-based smartphone," in 2010 International Conference on Information and Communication Technology Convergence, ICTC 2010, 2010, pp. 319320.

[5] Y.-C. Lai, F. Han, Y.-H. Yeh, C.-N. Lai, and Y.-C. Szu, "A GPS navigation system with QR code decoding and friend positioning in smart phones," in 2010 2nd International Conference on Education Technology and Computer, 2010, pp. V5-66 - V5-70.

[6] X. Shu, Z. Du, and R. Chen, "Research on Mobile Location Service Design Based on Android," in 5th International Conference on Wireless Communications, Networking and Mobile Computing, 2009, pp. 1-4.
[7] J. Saranya and J. Selvakumar, "Implementation of children tracking system on android mobile terminals," in 2013 International Conference on Communications and Signal Processing (ICCSP), 2013, pp. 961-965.

[8] J. T. B. Fajardo and C. M. Oppus, "A Mobile Disaster Management System Using the Andriod Technology,” WSEAS Trans. Commun., vol. 3, no. 3, pp. 77-86, 2009.

[9] D. E. Avison and G. Fizgeralds, Information Systems Development: Methodologies, Techniques, and Tools 4th edition. 2006.

[10] S. W. Ambler, The Elements of UML 2.0 Style. United States of America: Cambridge University Press, 2005. 